\title{
Diagnosis of Ketotic Hypoglycaemia of Childhood
}

\author{
B. F. HABBICK,* A. S. MCNEISH, $\dagger$ and J. B. P. STEPHENSON \\ From the Royal Hospital for Sick Children, Glasgow
}

\begin{abstract}
Habbick, B. F., McNeish, A. S., and Stephenson, J. B. P. (1971). Archives of Disease in Childhood, 46, 295. Diagnosis of ketotic hypoglycaemia of childhood. Twenty cases of ketotic hypoglycaemia have been diagnosed in one medical unit in the past 8 years. Typically the children were 'dysmature' at birth, with a history suggesting hypoglycaemia in the first 36 hours of life, and they have remained small and thin. 4 are the smaller of non-identical twins.

Most presented acutely with recurrent early morning convulsions after the age of 1 year. A dietary ketogenic provocation test, which is the standard diagnostic procedure, induced hypoglycaemia in the 19 cases in which it was done, but the children frequently remained asymptomatic. This contrasts with the original description of the test.

Treatment with carbohydrate supplements at bedtime has been successful in controlling symptoms in 16 of the 19 children followed up. Of the failures, 1 is attributable to parental non-co-operation, while in 2 others the original diagnosis was possibly erroneous.
\end{abstract}

Ketotic hypoglycaemia may be the most common type of childhood hypoglycaemia after the neonatal period (Senior and Loridan, 1969). However, the specificity of the condition has been questioned (Kogut, Blaskovics, and Donnell, 1969) and the diagnostic criteria remain imprecise. The usual confirmatory test is to induce symptomatic hypoglycaemia by means of a standard ketogenic diet (Colle and Ulstrom, 1964).

This paper describes the considerable variation encountered in the results of the dietary ketogenic provocation test when applied to 20 children with ketotic hypoglycaemia, who, on grounds of presentation and subsequent course, otherwise conformed to a unified clinical pattern. This casts doubt upon the value of this test as a discriminatory test in hypoglycaemia.

\section{Patients}

Details of the clinical features of the patients are recorded in Table I.

Since 1962, 24 non-diabetic children with symptomatic hypoglycaemia have been admitted to one medical unit of the Royal Hospital for Sick Children, Glasgow.

Received 29 July 1970.

^Present address: Associate Medical Clinic, Prince Albert, Saskatchewan, Canada.

†Present address: Children's Hospital, Ladywood, Birmingham, England.
Of these, 2 had infective hepatitis and 2 had dysentery and have been excluded from further discussion. The remaining 20 children form the basis of the present study. One has been reported previously (Stephenson and Hainsworth, 1966).

Age at diagnosis. This varied from 13 months to 5 years 11 months.

Sex. There were 14 boys and 6 girls.

Criteria of hypoglycaemia. All had blood glucose levels of less than $40 \mathrm{mg} / 100 \mathrm{ml}$, and symptoms of hypoglycaemia which were abolished by administration of glucose.

Mode of presentation. 17 of the 20 children were admitted to hospital as emergencies. The history of the preceding events in each case was very similar. Usually the child was well when he went to bed the previous evening, though occasionally there was a coexistent mild upper respiratory infection, and/or he did not eat his evening meal. On the morning of admission he slept longer than usual, and was still unrousable at 9 a.m. or 10 a.m. Later vomiting occurred, followed by a generalized clonic convulsion. In 1 case only focal twitching of an arm was noted, while 2 further cases had no observed convulsion but remained drowsy. The 3 children in the series who were not admitted as emergencies had a past history of early morning convulsions. Hypoglycaemia was later confirmed in each case, either as a spontaneous occur- 
TABLE I

Details of Previous History and Presenting Features

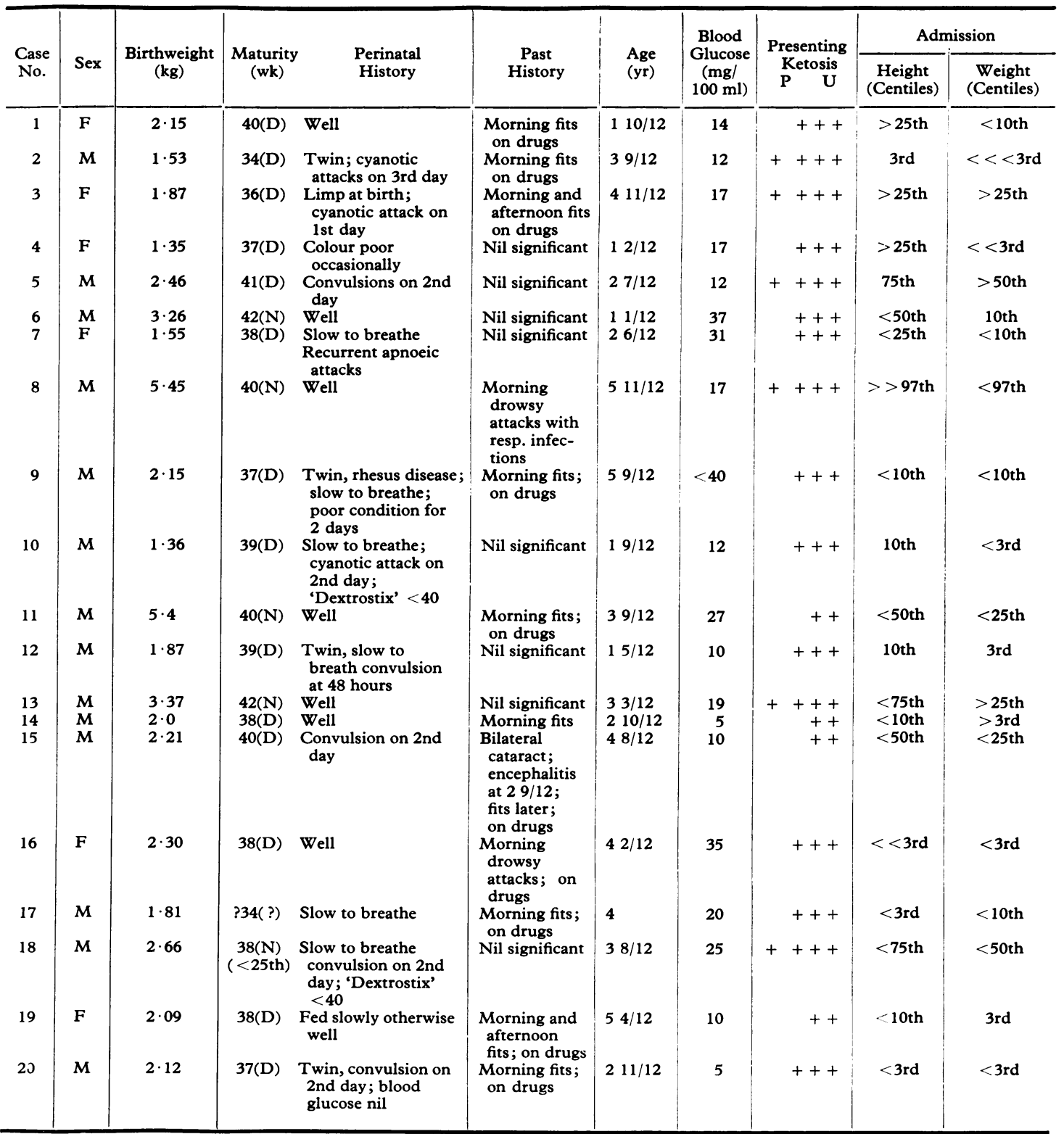

D, dysmature; $N$, normal; $P$, plasma ; U, urine.

rence, or as a result of a provocation test. While hypoglycaemic, all 20 patients were drowsy or unconscious and had marked ketonaemia and/or ketonuria. Each responded rapidly to oral or intravenous glucose. None was febrile.
Birthweight. Many were 'light for dates' (dysmature). All 6 girls and 8 of 14 boys were below the 10th centile of weight for maturity (Lubchenco et al., 1963). A further boy of unknown gestational age was $1 \cdot 81 \mathrm{~kg}$ at birth. 


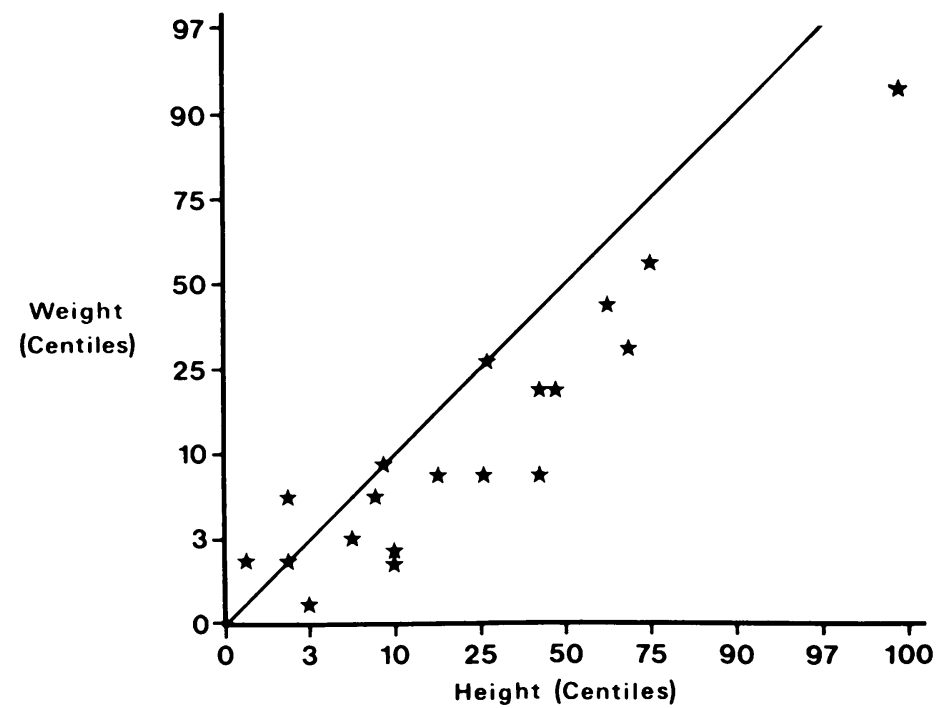

FIG. 1.-Diagrammatic representation of height-weight relation. Case 4 has been omitted.

Perinatal history. Of the 14 dysmature children, 6 required extensive resuscitation, and 5 of these 6 and 4 others had either cyanotic attacks, convulsions, or a generally poor condition in the first $\mathbf{4 8}$ hours of life. In only 2 of these was the blood glucose measured either directly or by 'Dextrostix' (Ames and Co.) readings, and in each case it was found to be less than $40 \mathrm{mg} / 100 \mathrm{ml}$.

Of the 5 children definitely not dysmature, 4 had no resuscitative or early neonatal problems. The fifth a boy whose birthweight for gestational period was between the 10th and 25th centiles, had prolonged apnoea at birth and convulsions at 36 hours associated with a 'Dextrostix' reading of less than $40 \mathrm{mg} / 100 \mathrm{ml}$.

Psychomotor development. No detailed measurements are available. 2 children (Cases 3 and 16) are grossly retarded.

Stature (Fig. 1). Most of the children are small and thin. Only 4 are above the 50th centile for height. One boy whose height is well above the 97th centile is also unusual in that hypoglycaemic attacks persist at the age of 8 years (see below).

Past history of convulsions. 12 children had a previous history of convulsions, which were confined to the early morning in 10 . Anticonvulsant therapy was taken regularly by 10 children.

There was an average delay of 2 years between the onset of symptoms and the diagnosis of hypoglycaemia.

Family history. 2 children had sibs with a history of convulsions. There was no family occurrence of diabetes mellitus.
Twins. 4 boys were each the smaller and lighter of non-identical twins.

Investigations (Table II)

Glucagon test (Fig. 2). After an overnight fast, a specimen of blood was taken for blood glucose estima-

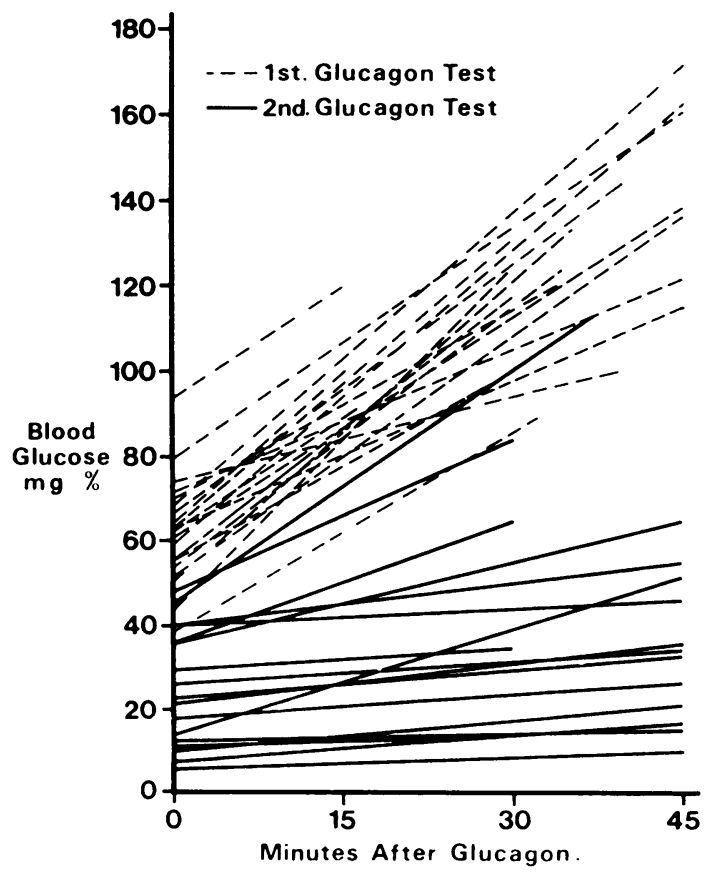

Fig. 2.-Response of blood glucose to glucagon administration before and after the ketogenic provocation test. 
TABLE II

Investigations and Follow-up

\begin{tabular}{|c|c|c|c|c|c|c|}
\hline \multirow{2}{*}{$\begin{array}{l}\text { Case } \\
\text { No. }\end{array}$} & \multirow{2}{*}{\multicolumn{2}{|c|}{$\begin{array}{cc}\text { Glucagon } & \text { Tests } \\
1 & 2\end{array}$}} & \multirow{2}{*}{$\begin{array}{l}\text { Clinical State at End of } \\
\text { Ketogenic Provocation Test }\end{array}$} & \multirow[b]{2}{*}{ EEG } & \multicolumn{2}{|r|}{ Follow-up } \\
\hline & & & & & $\begin{array}{l}\text { Duration } \\
(y r)\end{array}$ & Course of Illness \\
\hline $\begin{array}{r}8 \\
9 \\
10 \\
11 \\
12 \\
13 \\
14 \\
15 \\
16 \\
17 \\
18 \\
19 \\
20\end{array}$ & $\begin{array}{l}38-99 \star \\
74-100 \\
67-145 \\
44-125 \\
79-179 \\
64-101 \\
52-134 \\
\\
70-121 \\
60-140 \\
63-132 \\
59-120 \\
94-110 \\
52-138 \\
59-164 \\
61-89 \\
68-173 \\
55-118 \\
72-122 \\
56-100 \\
62-117\end{array}$ & $\begin{array}{l}\text { Test not done } \\
19-26 \\
22-33 \\
8-17 \\
40-46 \\
26-34 \\
10-16 \\
\\
30-36 \\
48-84 \\
14-47 \\
12-14 \\
40-58 \\
36-65 \\
46-114 \\
12-17 \\
35-66 \\
22-35 \\
15-\dagger \\
10-\dagger \\
6-14\end{array}$ & $\begin{array}{l}\text { Drowsy, disorientated } \\
\text { Well } \\
\text { Well } \\
\text { Vomited, lethargic } \\
\text { Lethargic } \\
\text { Well } \\
\text { Well } \\
\text { Well } \\
\text { Well } \\
\text { Vomited, drowsy } \\
\text { Well } \\
\text { Well } \\
\text { Well } \\
\text { Drowsy } \\
\text { Drowsy } \\
\text { Drowsy } \\
\text { Vomited, drowsy } \\
\text { Very drowsy within } 12 \mathrm{hr} \\
\text { Vomited, lethargic }\end{array}$ & $\begin{array}{l}\mathrm{N} \\
\text { Abn, then } \mathrm{N} \\
\text { Abn (persistent) } \\
\mathrm{N} \\
\mathrm{N} \\
-\mathrm{N} \\
\mathrm{N} \\
\mathrm{N} \\
-\mathrm{Abn} \text {, then } \mathrm{N} \\
- \\
-\mathrm{Abn}, \text { then } \mathrm{N} \\
\mathrm{N} \\
\mathrm{N} \\
\text { Abn, then } \mathrm{N} \\
\mathrm{N} \\
\mathrm{N} \\
\text { Abn (persistent) }\end{array}$ & $\begin{array}{l}5 \\
4 \\
3 \cdot 5 \\
3 \\
1 \cdot 75 \\
1 \cdot 75 \\
2 \cdot 25 \\
2 \cdot 5 \\
2 \\
\text { Not seen } \\
1 \cdot 75 \\
1 \\
1 \cdot 5 \\
1 \\
1 \\
0 \cdot 5 \\
0 \cdot 75 \\
0 \cdot 75 \\
0 \cdot 5 \\
0 \cdot 5\end{array}$ & $\begin{array}{l}\text { Well } \\
\text { Further fits; nil for } 2.5 \mathrm{yr} \\
\text { Retarded; fits when normoglycaemic } \\
\text { Further fits; nil for } 1.75 \mathrm{yr} \\
\text { Further fits; nil for } 1.5 \mathrm{yr} \\
\text { Well } \\
\text { Hypoglycaemic with dysentery } \\
\quad \text { Then nil for } 1.5 \mathrm{yr} \\
\text { Further fits } \\
\text { Well } \\
\text { Well } \\
\text { Well } \\
\text { Well } \\
\text { Well } \\
\text { Further fit, then well for } 0.5 \mathrm{yr} \\
\text { Retarded; no further fits } \\
\text { Further fits (advice not followed) } \\
\text { Well } \\
\text { Further fits } \\
\text { Further fits, even when normoglycaemic }\end{array}$ \\
\hline
\end{tabular}

$\star$ Blood glucose in $\mathrm{mg} / 100 \mathrm{ml}$, fasting level, and highest level after glucagon given.

tGlucagon test not done.

$\mathrm{N}=$ Normal; Abn $=$ Abnormal

tion, then glucagon $30 \mu \mathrm{g} / \mathrm{kg}$ given intramuscularly. Further blood specimens for glucose estimation were taken at 15-minute intervals for 1 to $1 \frac{1}{2}$ hours. All children had a satisfactory hepatic release of glucose.

Ketogenic provocation test. After a preparatory period of 3 days on a high carbohydrate diet, the patient was given a low calorie, high fat diet and his response was monitored, as described by Colle and Ulstrom (1964). Of the 19 patients who had the test, 17 had a blood glucose of less than $40 \mathrm{mg} / 100 \mathrm{ml}$ within 24 hours of starting the test, while in the other 2 children the blood glucose fell to $46 \mathrm{mg} / 100 \mathrm{ml}$ and $48 \mathrm{mg} / 100 \mathrm{ml}$, respectively. The clinical response was very variable. In 10 patients symptoms and signs consistent with hypoglycaemia appeared, e.g. diminished activity, drowsiness, pallor, and vomiting. No patient had a convulsion, even though the blood glucose was $30 \mathrm{mg} /$ $100 \mathrm{ml}$ or less in 13 cases and less than $20 \mathrm{mg} / 100 \mathrm{ml}$ in 9. Some patients who had had previous convulsions associated with documented hypoglycaemia remained well despite severe hypoglycaemia at the end of the test period. Electroencephalographic evidence of neuroglycopenia was sought at the end of the test in 6 children (see below). 3 had an abnormal tracing, which reverted to normal in 2 cases after restoration of normal blood glucose levels. A glucagon test (Fig. 2) was repeated at the end of 24 hours in 17 cases. A 'flat' curve was found in 12, while 5 had a rise on blood glucose of at least $20 \mathrm{mg} / 100 \mathrm{ml}$ after glucagon administration.

Plasma cortisol. This was estimated at the time of hypoglycaemia in 10 children, and was greatly raised in 9, indicating a normal hypothalamic-pituitaryadrenal mechanism. In the 10th patient (Case 19) the plasma cortisol failed to increase in response to hypoglycaemia on two occasions, though her fasting levels of plasma cortisol were normal (see below).

EEG. 16 children had at least one EEG, 6 showing an abnormality either at the time of the hypoglycaemic attack or within 1 to 2 days of admission. In 2 of these this merely consisted of an increase in slow wave activity, but the remainder showed recurrent spike or polyspike activity with an occasional irregular spike and wave pattern. In 2 of these the abnormality persisted after recovery from the acute episode.

Skull x-ray. This was normal in each case.

Other investigations. None of the children had features of a glycogenosis, leucine sensitivity, or fructose intolerance. Leucine tests were performed on 2 patients only, and were normal. Intravenous tolbutamide tests on 4 patients evoked normal responses of blood glucose and plasma insulin.

\section{Subsequent Course of Patients}

The parents were advised to give each child a carbohydrate snack at bedtime, e.g. a glass for milk and 2 biscuits, and to ensure that he was wakened for breakfast by 8 a.m. Some parents were also instructed to test the child's urine at bedtime with 'Ketostix' (Ames and 
Co.). If ketonuria was found, further carbohydrate was added to the usual snack.

We have managed to follow up 19 of the 20 children satisfactorily for periods ranging from 6 months to 5 years : 9 have had no further hypoglycaemia, and 1 had only a single further episode when she had dysentery. The 2 children with persistently abnormal EEG's have required anticonvulsant therapy to control further convulsions which are no longer associated with hypoglycaemia.

Seven patients have had recurring hypoglycaemic attacks. In $\mathbf{5}$ of these cases, the parents did not follow the advice about diet. 4 were persuaded to co-operate, and their children have been well since.

The 2 children who continue to have hypoglycaemic attacks while adhering to the dietary regimen are unusual in several respects. One is a very tall 8-year-old boy whose brother died in status epilepticus aged 3 years. Extensive investigation has failed to reveal an insulinoma and his symptoms are only partially controlled by a high carbohydrate diet. The other patient fails to show a rise in plasma cortisol when hypoglycaemic, with normal basal levels; synacthen and metyrapone tests are normal. A hypothalamic lesion is possible but has not been proven.

\section{Discussion}

Hitherto the diagnosis of ketotic hypoglycaemia has depended not only on clinical criteria but also on the occurrence of acetonuria, symptomatic hypoglycaemia, and failure to respond to glucagon, after the administration of a ketogenic diet (Colle and Ulstrom, 1964). Though each of our patients presented with hypoglycaemia and ketosis, several failed to fulfil the other investigative criteria of ketotic hypoglycaemia, either because they did not have symptomatic hypoglycaemia or because they showed a response to glucagon. It is possible that these criteria would have been satisfied if the ketogenic provocation test had been continued beyond 24 hours, but we did not consider this to be justified, since in the original description of the test, Colle and Ulstrom's patients developed symptoms within 20 hours of starting the diet, i.e. within 4 to 12 hours of the appearance of acetonuria. The patients who did not fulfil these criteria appeared no different from the group as a whole in respect of birthweight, sex, past history, age, and stature, nor did their subsequent course differ from that of the others. Conversely, the 2 patients who were thought to have features which stamped them as different from the others, i.e. Cases 8 and 19, failed to respond to glucagon after ketogenic diets, and Case 19 was one of the patients who did develop symptomatic hypoglycaemia. It is of interest that several normal children who were given a ketogenic diet by Colle and Ulstrom (1964) deve- loped hypoglycaemia (though none had symptoms) and some failed to respond to glucagon. Senior and Loridan (1969) also observed hypoglycaemia after deprivation of carbohydrate and calories, not only in children with ketotic hypoglycaemia but also in control children. Our experience leads us to suggest that not enough information is available about the response of hypoglycaemic and of normal children to a ketogenic diet to enable us to say that its administration to a patient with hypoglycaemia will enable us to identify the ketotic variety.

It has been suggested by Kogut et al. (1969) that ketotic hypoglycaemia may not be a specific entity. The occurrence of hypoglycaemia in association with ketosis in children under the age of 5 years might be expected, since the data of Colle and Ulstrom (1964) and of Senior and Loridan (1969) suggest that hypoglycaemia might be a normal accompaniment of deprivation of calories in children, while Kaye et al. (1961) showed that children aged 1 week to 4 years developed more ketosis on fasting than did older children. However, a specific aetiological mechanism is suggested by the similarity of the clinical pattern in the majority of cases. Colle and Ulstrom (1964) felt that their patients differed from other children with hypoglycaemia in their clinical course which is characterized by a relatively late onset, long periods of good health between the episodes, and ease of control of symptoms with diet alone. A study has just been completed of 50 children admitted because of a convulsion to the same medical unit as the one to which the hypoglycaemic children were admitted. This study emphasizes the differences in the clinical pattern between these two groups of children whose major presenting feature was a convulsion (Shepherd et al., 1970).

Though it has been pointed out by others (Colle and Ulstrom, 1964; Kogut et al., 1969) that patients with ketotic hypoglycaemia are often of low birthweight, perhaps it has not been sufficiently emphasized that their birthweight is low in relation to the length of their gestation, i.e. they are dysmature. Neligan, Robson, and Watson (1963) described a hypoglycaemic, dysmature neonate who was readmitted to hospital at age 1 year with hypoglycaemia. There may be a metabolic disturbance in dysmature babies which makes them susceptible to hypoglycaemia in both the neonatal period and in later childhood (Cox and Dunn, 1967). One such disturbance could be impaired gluconeogenesis, but Senior and Loridan (1969) could not show any evidence of this.

The finding of hypoglycaemia in 4 boys who were 
the smaller and lighter of non-identical twins recalls the experience of Reisner, Forbes, and Cornblath (1965) who found neonatal hypoglycaemia in 11 infants, each of whom was the smaller of twins, and of Oseid and Aagenaes (1967) who described hypoglycaemia in a 4-year-old boy who was the smaller of twins.

All except 3 of our cases have been diagnosed since 1966, and we feel that this reflects greater awareness of the diagnosis rather than a true increase in incidence. Hypoglycaemia should be suspected in a young child who presents in the early morning in a drowsy state or with a convulsion, the suspicion of hypoglycaemia being reinforced by an absence of fever, by a history of dysmaturity, and by the finding that the child is smaller and thinner than normal.

We thank the various consultants who gave us permission to report their patients; Dr. R. A. Shanks who reported the EEGs, Dr. R. W. Logan and the technicians of the Biochemistry Department for help; Doctors I. C. Ferguson and $M$. Le Dune for plasma insulin estimations; Dr. W. Hamilton for urinary steroid estimations; and Mr. J. Devlin and Miss Janet Watson of the Photography Department for the preparation of figures.
REFERENCES

Colle, E., and Ulstrom, R. A. (1964). Ketotic hypoglycemia. Fournal of Pediatrics, 64, 632.

Cox, M., and Dunn, H. G. (1967). Idiopathic hypoglycaemia and children of low birth-weight. Developmental Medicine and Child Neurology, 9, 430.

Kaye, R., Davidson, M. H., Williams, M. L., Kumagai, M., and Picou, D. M. (1961). The response of blood glucose, ketones, and plasma nonesterified fatty acids to fasting and epinephrine injection in infants and children. Fournal of Pediatrics, 59, 836.

Kogut, M. D., Blaskovics, M., and Donnell, G. N. (1969). Idiopathic hypoglycemia: a study of twenty-six children. Fournal of Pediatrics, 74, 853.

Lubchenco, L. O., Hansman, C., Dressler, M., and Boyd, E. (1963). Intrauterine growth as estimated from liveborn birth-weight data at 24 to $\mathbf{4 2}$ weeks of gestation. Pediatrics, 32, 793.

Neligan, G. A., Robson, E., and Watson, J. (1963). Hypoglycaemia in the newborn. A sequel of intrauterine malnutrition. Lancet, 1, 1282.

Oseid, S., and Aagenaes, Ø. (1967). The smaller of twins and hypoglycemia. Acta Paediatrica, Suppl., 177, 114.

Reisner, S. H., Forbes, A. E., and Cornblath, M. (1965). The smaller of twins and hypoglycaemia. Lancet, 1, 524.

Senior, B., and Loridan, L. (1969). Gluconeogenesis and insulin in the ketotic variety of childhood hypoglycemia and in control children. Fournal of Pediatrics, 74, 529.

Shepherd, R. C., McMorris, S., Habbick, B. F., and McNeish, A. S. (1970). A study of blood glucose following convulsions in children. To be published.

Stephenson, J. B. P., and Hainsworth, I. R. (1966). Ketotic hypoglycaemia of childhood. Proceedings of the Association of Clinical Biochemists, 5, 80 .

Correspondence to Dr. J. B. P. Stephenson, Royal Hospital for Sick Children, Glasgow, Scotland. 